Obere Extremität 2018 · 13:269-272

https://doi.org/10.1007/s11678-018-0489-6

Received: 11 July 2018

Accepted: 6 September 2018

Published online: 7 November 2018

(c) The Author(s) 2018

CrossMark

Pseudoparesis or pseudoparalysis is debilitating in young patients desiring an active lifestyle. This presentation is often associated with irreparable rotator cuff tears with no or minimal degenerative changes. Attempts at surgical repair often result in a high re-tear rate [9]. Although reverse total shoulder arthroplasty results in effective pain relief, this option is often reserved for patients with degenerative changes and a less active lifestyle [17]. Tendon transfer surgery has become a more accepted treatment option for irreparable rotator cuff tears in patients desiring greater postoperative function, particularly strength and range of motion [8, 10, 13, 14]. Specifically, the lower trapezius tendon transfer with Achilles tendon allograft augmentation is indicated for massive irreparable posterosuperior rotator cuff tears in patients with limited degenerative changes as well as in patients with paralytic shoulders following nerve injuries.

\section{Indications}

The lower trapezius tendon transfer with Achilles tendon allograft augmentation is indicated for massive irreparable posterosuperior rotator cuff tears and for paralytic shoulders lacking active external rotation (• Fig. 1).

Absolute contraindications include active soft tissue infection or trapezius muscle paralysis, which may occur following trauma or prior to transfer of the spinal accessory nerve in treatment of brachial plexus injuries. Relative contraindications include advanced glenohumeral degenerative changes or

William R. Aibinder · Bassem T. Elhassan

Department of Orthopedic Surgery, Mayo Clinic, Rochester, USA

\title{
Lower trapezius transfer with Achilles tendon augmentation: indication and clinical results
}

inability of the patient to follow postoperative instructions.

Nonetheless, the basis of the procedure relies on several key principles of the glenohumeral articulation and rotator cuff balance. The glenohumeral articulation is an inherently unstable joint and relies heavily on the dynamic stabilization of the rotator cuff musculature [11]. In order for this to occur effectively, the transverse and coronal force couples must be intact and balanced [3]. Thus, the anterior subscapularis must be balanced relative to the posterior portion of the infraspinatus and teres minor; while the superior force provided by the deltoid must be balanced relative to the rotator cuff musculature inferior to the humeral head equator. This serves to maintain a concentric joint that facilitates shoulder function.

In the setting of shoulder paralysis, the static effect of the shoulder musculature maintains the glenohumeral articulation, but the shoulder lacks power to function. These patients are often limited by the lack of active external rotation, which has been shown to be important in many activities of daily living [2]. Thus, a lower trapezius tendon transfer in this setting aims to restore active external rotation and provide function.

In the setting of a massive irreparable posterosuperior rotator cuff tear, the force couples are often imbalanced and patients present with not only lack of function, but also significant pain and debility [14]. A lower trapezius tendon transfer in this setting aims to primarily relieve pain, but also to provide strength and function. The anterior portion of the transverse couple must be intact, or if torn, must be recreated by tendon transfer or repair. Ultimately, the goal is to reverse pseudoparesis or pseudoparalysis of the shoulder.

The biomechanical rationale for the lower trapezius tendon transfer is based on two key studies [12, 15]. Hartzler et al. demonstrated that the external rotation moment arm with the arm at the side was greatest with the lower trapezius transfer. Omid et al. demonstrated that the native glenohumeral kinematics and joint reactive forces were most closely recreated when the lower trapezius transfer was performed. In essence, the osseous concentricity of the joint is best recreated with the lower trapezius tendon transfer allowing for the greatest improvements in range of motion. Additionally, it appears that the trapezius muscle demonstrates electrical recruitment during active external rotation.

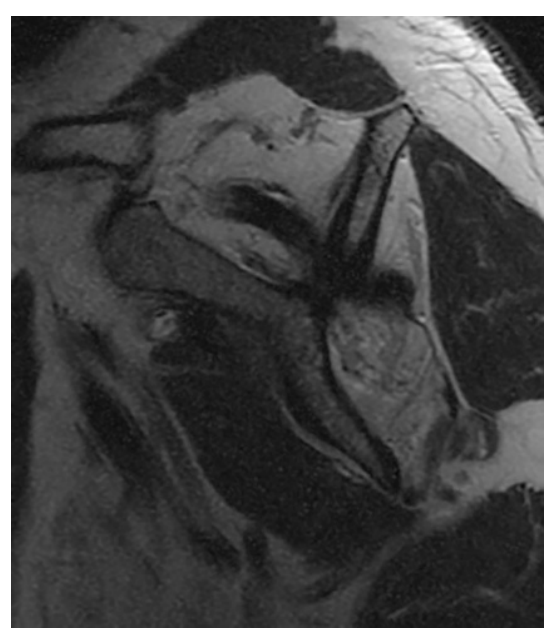

Fig. 1 \& Sagittal T1-weighted magnetic resonance image demonstrating significant atrophy of the supraspinatus and infraspinatus tendons, representative of an irreparable rotator cuff tear 
Achilles tendon allograft augmentation is required in all cases of irreparable rotator cuff tears owing to the short excursion of the lower trapezius tendon (- Figs. 2 and 3). Augmentation, however, is not indicated in all cases of shoulder paralysis as long as the integrity and caliber of the infraspinatus tendon are adequate.

\section{Clinical results}

\section{Paralytic shoulder}

Promising results have reported of lower trapezius tendon transfer for an indication of shoulder paralysis with absent active external rotation. Although there is a paucity of data, several case reports and case series exist utilizing ipsilateral lower trapezius tendon transfer for restoration of active external rotation in brachial plexus injuries (•Table 1). Bertelli reported on seven adult patients who regained a mean of $104^{\circ}$ of active external rotation as measured from the abdomen [1]. Elhassan et al. reported improvements in active external rotation in $46 \mathrm{pa}$ tients $[4,5]$.

In many cases of shoulder paralysis, however, the ipsilateral trapezius is often compromised owing to the inciting trauma or because of initiating reconstructive efforts using transfer of the spinal accessory nerve. Thus, several authors have used the contralateral lower trapezius muscle transfer to restore active external rotation. Satbhai et al. reported on three cases of shoulder paralysis treated with a contralateral lower trapezius tendon transfer [16]. Active external rotation improved in all cases with a mean of $97^{\circ}$ of motion. Additionally, the authors noted significant improvements in functional outcomes. Elhassan et al. reported on 12 patients undergoing a contralateral lower trapezius tendon transfer [7]. Active external rotation improved in ten $(83 \%)$ patients with a mean of $110^{\circ}$ of motion from the abdomen. In the two failures, one patient underwent plication of the transfer following a trauma, while the other refused further treatment. These early reports demonstrate promising early outcomes. The latter study did not identify any ef-

Obere Extremität 2018 · 13:269-272 https://doi.org/10.1007/s11678-018-0489-6

(c) The Author(s) 2018

\section{W. R. Aibinder · B. T. Elhassan}

\section{Lower trapezius transfer with Achilles tendon augmentation: indication and clinical results}

\section{Abstract}

Lower trapezius tendon transfer with Achilles tendon allograft augmentation may be used to treat patients with lack of active external rotation following shoulder paralysis or massive irreparable posterosuperior rotator cuff tears. In the setting of shoulder paralysis, the integrity of the ipsilateral lower trapezius may be compromised. In this instance, the contralateral lower trapezius may be used with reasonable results. In the setting of irreparable rotator cuff tears, the procedure may be performed through an open or arthroscopically assisted technique. The latter avoids the need for an acromial osteotomy and risk of nonunion associated with repair of the osteotomy. Both are effective in reversing pseudoparesis or pseudoparalysis. Advanced degenerative changes have an effect on outcomes, resulting in less pain improvement, decreased range of motion, and greater need for reoperation with conversion to reverse total shoulder arthroplasty. Nonetheless, the lower trapezius tendon transfer is an effective option for restoring active external rotation with relatively consistent results.

\section{Keywords}

External rotation - Tendon transfer .

Pseudoparalysis · Shoulder injuries · Rotator cuff tear

\section{Unterer Trapeziustransfer mittels Achillessehnenaugmentation: Indikation und klinische Ergebnisse}

\section{Zusammenfassung}

Der Transfer der unteren Trapeziussehne mit Augmentation durch ein Achillessehnen-Allotransplantat kann zur Therapie von Patienten mit mangelnder aktiver Außenrotation nach Schulterlähmung oder massiven irreparablen posterosuperioren Rotatorenmanschettenrupturen eingesetzt werden. Bei Vorliegen einer Schulterlähmung kann die Integrität des ipsilateralen unteren M. trapezius beeinträchtigt sein. In diesem Fall kann der kontralaterale M. trapezius mit akzeptablen Ergebnissen verwendet werden. Liegt eine irreparable Rotatorenmanschettenruptur vor, so kann die Therapie über eine offene Operation oder arthroskopisch erfolgen. Bei Letzterer werden die Notwendigkeit einer akromialen Osteotomie und das Risiko einer Pseudarthrose bei deren
Heilung vermieden. Beide Verfahren eignen sich zur Beseitigung einer Pseudoparese oder Pseudoparalyse. Fortgeschrittene degenerative Veränderungen wirken sich auf das Ergebnis aus, führen zu einer geringeren Schmerzlinderung, vermindertem Bewegungsumfang und höherem Bedarf an Reoperationen mit Konversion zur reversen totalen Schulterarthroplastik. Trotzdem stellt der Transfer der unteren Trapeziussehne eine wirksame Option zur Wiederherstellung der aktiven Außenrotation mit relativ konstanten Ergebnissen dar.

\section{Schlüsselwörter}

Außenrotation - Sehnentransfer . Pseudoparalyse $\cdot$ Schulterläsionen . Rotatorenmanschettenruptur fects of the transfer on shoulder function of the donor side.

\section{Irreparable posterosuperior rotator cuff tear}

Open lower trapezius tendon transfer surgery for irreparable posterosuperior rotator cuff tears has been shown to result in significant improvements in pain and range of motion in 32 of 33 patients a mean follow-up of 47 months [8]. Most noteworthy is restoration of strength and range of motion. An external rotation lag sign, which was present in $82 \%$ of patients, resolved universally. All patients had a minimum of grade 4 out of 5 muscle strength on manual external rotation strength testing. External rotation pseudoparesis or pseudoparalysis resolved in all cases. Several complications have also been reported. Four patients were noted to have a seroma, which was successfully treated conservatively. One patient 


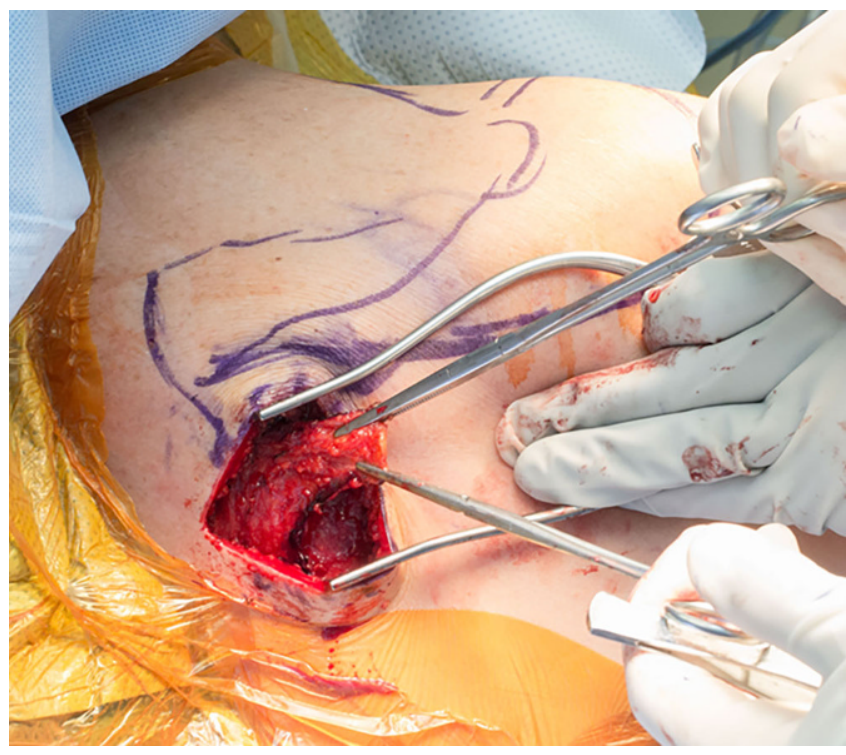

Fig. 2 Harvesting of the lower trapezius tendon through a horizontal incision along the medial aspect of the scapular spine. Note the triangular shape of the tendon

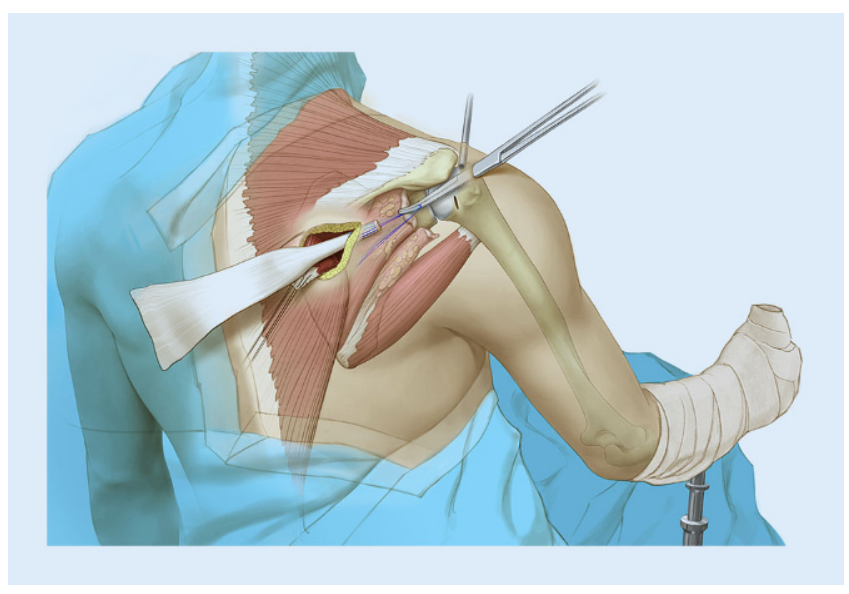

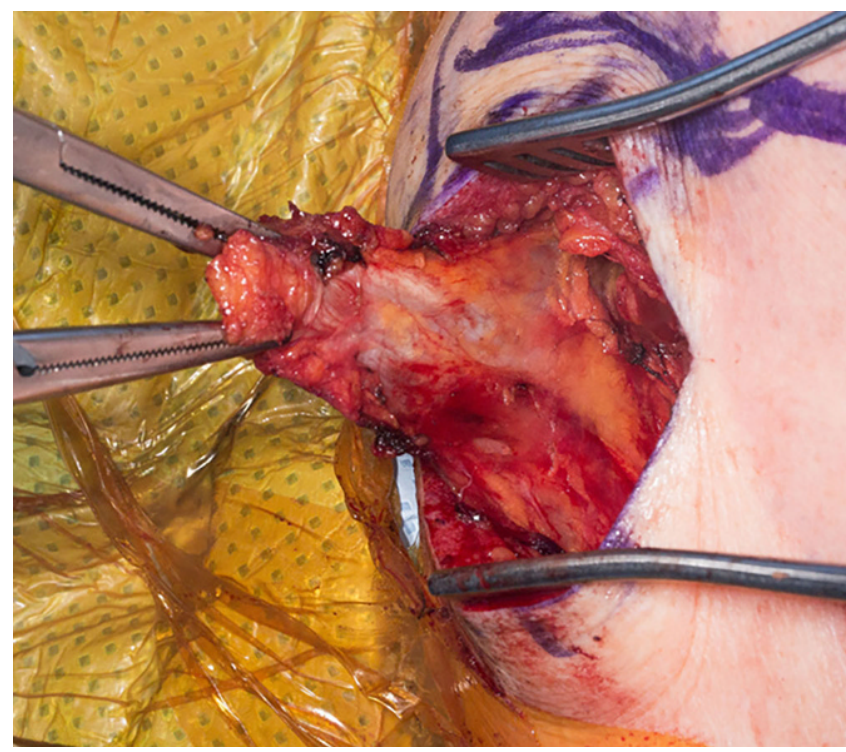

Fig. $3 \Delta$ Medial dissection on the under-surface of the tendon allows for maximal excursion and interdigitation with the Achilles tendon allograft

Fig. $4<$ Schematic drawing demonstrating the passage of the Achilles tendon autograft through the lateral arthroscopic portal. (Used with permission of the Mayo Foundation for Medical Education and Research. All rights reserved)

Table 1 Summary of recent studies evaluating lower trapezius tendon transfer for restoration of active external rotation

\begin{tabular}{|lll|l|l|}
\hline & Indication & Technique & Patients & $\begin{array}{l}\text { Final External } \\
\text { Rotation }\end{array}$ \\
\hline $\begin{array}{l}\text { Bertelli } \\
(2011 ;[1])\end{array}$ & $\begin{array}{l}\text { Shoulder } \\
\text { paralysis }\end{array}$ & Open & 7 & $104^{\circ}$ (from abdomen) \\
$\begin{array}{l}\text { Satbhai et al. } \\
(2014 ;[16])\end{array}$ & $\begin{array}{l}\text { Shoulder } \\
\text { paralysis }\end{array}$ & $\begin{array}{l}\text { Contralateral } \\
\text { open }\end{array}$ & 3 & $97^{\circ}$ (from abdomen) \\
$\begin{array}{l}\text { Elhassan et al. } \\
(2016 ;[7])\end{array}$ & $\begin{array}{l}\text { Shoulder } \\
\text { paralysis }\end{array}$ & $\begin{array}{l}\text { Contralateral } \\
\text { open }\end{array}$ & 12 & $110^{\circ}$ (from abdomen) \\
$\begin{array}{l}\text { Elhassan et al. } \\
(2016 ;[8])\end{array}$ & $\begin{array}{l}\text { Irreparable } \\
\text { rotator cuff tear }\end{array}$ & Open & 33 & $50^{\circ}$ (from neutral) \\
$\begin{array}{l}\text { Elhassan et al. } \\
\text { (unpublished) }\end{array}$ & $\begin{array}{l}\text { Irreparable } \\
\text { rotator cuff tear }\end{array}$ & $\begin{array}{l}\text { Arthroscopically } \\
\text { assisted }\end{array}$ & 37 & $47^{\circ}$ (from neutral) \\
\hline
\end{tabular}

required a glenohumeral arthrodesis for a persistent infection. Another patient was noted to have failure of the transfer following a fall.

The open technique requires an acromial osteotomy to expose the humeral head. Radiographically, $24 \%$ of patients demonstrated incomplete healing, which did not affect outcomes. Nonetheless, a nonunion of the acromial osteotomy is worrisome.

An arthroscopically assisted technique has been described for a lower trapezius tendon transfer with Achilles tendon allograft augmentation ([6]; - Fig. 4). The main purpose was to avoid violating the acromion and deltoid for exposure, and thus preventing nonunion of the acromial osteotomy. Additionally, arthroscopy improves visualization of the subscapularis tendon and facilitates repair.

The senior author (Bassem T. Elhassan) has performed an arthroscopically assisted lower trapezius tendon transfer on 41 patients. In a recent retrospective review (currently pending publication), at a mean follow-up of 13 months, 37 (90\%) patients were found to have improvements in all outcome measures. Pseudoparalysis was reversed in more than $90 \%$ of patients. Reparable subscapularis tears did not affect outcomes. Degenerative changes, however, particu- 
larly Hamada stage 2 and 3 changes, led to worse outcomes in regard to pain and range of motion. Thus, lower trapezius tendon transfer in patients with advanced degenerative changes should be avoided or at least patients should be counselled on the likely risk of persistent pain and need for further surgery, such as a reverse total shoulder arthroplasty.

\section{Practical conclusion}

- Lower trapezius tendon transfer with Achilles tendon allograft augmentation is an effective treatment for restoring active external rotation in patients with paralytic shoulders or irreparable posterosuperior rotator cuff tears.

- The procedure may be performed via an open technique or through an arthroscopically assisted procedure.

- For the procedure to be effective, surgeons should understand the principles and tenets of tendon transfer surgery as well as the biomechanics of glenohumeral articulation and rotator cuff force couples.

- For paralytic shoulders, careful evaluation of the integrity of the ipsilateral trapezius musculature is necessary. If compromised, the contralateral trapezius may be used.

- For irreparable rotator cuff tears, degenerative changes involving the glenohumeral joint must be evaluated on plain radiographs or magnetic resonance images. Advanced degenerative changes should prompt surgeons to recommend other treatment options, e.g., reverse total shoulder arthroplasty.

\section{Corresponding address}

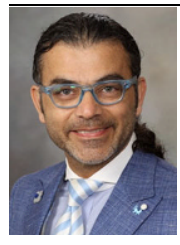

Bassem T. Elhassan, MD Department of Orthopedic Surgery, Mayo Clinic 200 First Street SW, 55905 Rochester, MN, USA Elhassan.Bassem@mayo.edu

\section{Compliance with ethical guidelines}

Conflict of interest. W.R. Aibinder and B.T. Elhassan declare that they have no competing interests.

All procedures performed in studies involving human participants were in accordance with the ethical standards of the institutional and/or national research committee and with the 1975 Helsinki declaration and its later amendments or comparable ethical standards. Informed consent was obtained from all individual participants included in the study.

Open Access This article is distributed under the terms of the Creative Commons Attribution 4.0 International License (http://creativecommons.org/licenses/by/ 4.0/), which permits unrestricted use, distribution, and reproduction in any medium, provided you give appropriate credit to the original author(s) and the source, provide a link to the Creative Commons license, and indicate if changes were made.

\section{References}

1. BertelliJA (2011) Upper and lower trapeziusmuscle transfer to restore shoulder abduction and external rotation in longstanding upper type palsies of the brachial plexus in adults. Microsurgery 31:263-267

2. Boileau P, Chuinard C, Roussanne Y et al (2007) Modified latissimus dorsi and teres major transfer through a single delto-pectoral approach for external rotation deficit of the shoulder: as an isolated procedure or with a reverse arthroplasty. J Shoulder Elbow Surg 16:671-682

3. Burkhart SS (1991) Arthroscopic treatment of massive rotator cuff tears. Clinical results and biomechanical rationale. Clin Orthop Relat Res 267:45-56

4. Elhassan B, Bishop A, Shin A (2009) Trapezius transfer to restore external rotation in a patient with a brachial plexus injury. A case report. J Bone Joint Surg Am 91:939-944

5. Elhassan B, Bishop A, Shin A et al (2010) Shoulder tendon transfer options for adult patients with brachial plexus injury. J Hand Surg Am 35:1211-1219

6. Elhassan BT, Alentorn-Geli E, Assenmacher AT et al (2016) Arthroscopic-assisted lower Trapezius tendon transfer for massive irreparable posteriorsuperior rotator cuff tears: surgical technique. Arthrosc Tech 5:e981-e988

7. Elhassan BT, Wagner ER, Spinner RJ et al (2016) Contralateral Trapezius transfer to restore shoulder external rotation following adult brachial plexus injury. JHand Surg Am 41:e45-e51

8. Elhassan BT, Wagner ER, Werthel JD (2016) Outcome of lower trapezius transfer to reconstruct massive irreparable posterior-superior rotator cuff tear. JShoulder Elbow Surg 25:1346-1353

9. Galatz LM, Ball CM, Teefey SA et al (2004) The outcome and repair integrity of completely arthroscopically repaired large and massive rotator cufftears. JBone Joint Surg Am 86-A:219-224

10. Gerber C, Rahm SA, Catanzaro $S$ et al (2013) Latissimus dorsi tendon transfer for treatment of irreparable posterosuperior rotator cuff tears: long-term results at a minimum follow-up of ten years. JBone Joint Surg Am 95:1920-1926

11. Hansen ML, Otis JC, Johnson JS et al (2008) Biomechanics of massive rotator cuff tears: implications for treatment. J Bone Joint Surg Am 90:316-325

12. Hartzler RU, Barlow JD, An KN et al (2012) Biomechanical effectiveness of different types of tendon transfers to the shoulder for external rotation. JShoulder Elbow Surg 21:1370-1376

13. Kany J, Guinand R, Croutzet P et al (2016) Arthroscopic-assisted latissimus dorsi transfer for subscapularis deficiency. Eur J Orthop Surg Traumatol 26:329-334

14. Merolla G, Chillemi C, Franceschini V et al (2014) Tendon transfer for irreparable rotator cuff tears: indications and surgical rationale. Muscles Ligaments Tendons J 4:425-432

15. Omid R, Heckmann N, Wang L et al (2015) Biomechanical comparison between the trapezius transfer and latissimus transfer for irreparable posterosuperior rotator cuff tears. J Shoulder Elbow Surg 24:1635-1643

16. Satbhai NG, Doi K, Hattori Y et al (2014) Contralateral lower trapezius transfer for restoration of shoulder external rotation in traumatic brachial plexus palsy: a preliminary report and literature review. J Hand Surg Eur Vol 39:861-867

17. Werner CM, Steinmann PA, Gilbart $M$ et al (2005) Treatment of painful pseudoparesis due to irreparable rotator cuff dysfunction with the Delta III reverse-ball-and-socket total shoulder prosthesis. JBone Joint Surg Am 87:1476-1486 